\title{
NÓS, CIBORGUES: O CORPO ELÉTRICO E A DISSOLUÇÃO DO HUMANO ANTROPOLOGIA DO CIBORGUE: AS VERTIGENS DO PÓS-HUMANO - DONNA HARAWAY, HARI KUNZRU, TOMAZ TADEU (ORG.). 2016
}

\author{
Lilliân Alves Borges (UFU) \\ Tamira Fernandes Pimenta (UFU) \\ Marcus Vinícius Lessa de Lima (UFU)
}

Recebido em 03 mai 2018. Lilliân Alves Borges é doutoranda em Estudos Literários Aprovado em 10 mai 2018. na Universidade Federal de Uberlândia- UFU. Vicelíder do Grupo de Pesquisas em Espacialidades Artísticas/CNPq. Membro do Nós do Insólito: vertentes da ficção, da teoria e da crítica- UERJ. Estudos com ênfase no espaço literário, narrativa fantástica, com interesse especial sobre a obra de Graciliano Ramos.

Tamira Fernandes Pimenta é mestranda em Estudos Literários na Universidade Federal de Uberlândia. Graduada em Letras/ Português e suas respectivas literaturas pela UFU. Integrante do GPEA - Grupo de Pesquisas em Espacialidades Artísticas/ CNPq . Pesquisadora cadastrada na FAPEMIG com a pesquisa intitulada: " Como escrever uma vida: O insólito na escrita e pintura Kahliana". Atualmente é bolsista CAPES e tem seus estudos com ênfase em literatura e outras artes, com interesse especial na obra da pintora mexicana Frida Kahlo. 
Marx, Freud, Nietzsche, Heidegger. As revisões de Lacan e de Althusser. Foucault, Deleuze, Derrida, Lyotard e os pós-estruturalistas. Estudos feministas. Estudos culturais de raça e etnia. Estudos pós-colonialistas. A partir desse "breve" elenco de sistemas teóricos, vemos mapear-se mais de dois séculos de demolição do sujeito cartesiano e da subjetividade racional, reflexiva,

Donna Haraway HARI KUNZR! TOMAZ TADEu (ORe:

Antropologia do ciborgue As vertigens do pós-humano autoconsciente: "não existe sujeito ou subjetividade fora da história e da linguagem, fora da cultura e das relações de poder" (TADEU, 2016, p.10).

Essa constatação é o ponto de partida e a base do pensamento que se descortinará na leitura dos quatro textos presentes no volume Antropologia do ciborgue: as vertigens do pós-humano, organizado e traduzido por Tomaz Tadeu (que assina também o primeiro ensaio). O livro contém ainda o relato de uma entrevista a Donna Haraway, conduzida por Hari Kunzru, além de uma tradução do canônico "Manifesto ciborgue" de Haraway, e um breve ensaio final também assinado por Kunzru.

A ruína conceitual do sujeito não é uma questão inédita, e os esforços contemporâneos abundam para pensá-la. Mais próxima ao âmbito da produção estética, Eliane Robert Moraes traz um exemplo desses esforços, ao investigar o problema da desfiguração do corpo humano e do desvio em relação à lógica antropomórfica na arte e no pensamento franceses do final do século XIX ao 
entreguerras $^{1}$. No campo editorial de vulgarização científica, em breve ensaio publicado na Revista CULT, Eduardo Leal Cunha, ao comentar a respeito das diversas configurações contemporâneas da homossexualidade, sugerirá que o colapso de uma identidade específica pode ressoar muito além, representando, na verdade, uma ruptura com a própria noção de identidade como elemento estruturante e organizador de um pensamento:

A suposta crise da identidade masculina poderá ser referida [...] ao colapso da própria lógica identitária, representada paradoxalmente pelo modo como as identidades e suas fronteiras se multiplicam continuamente [...], tornam-se inevitavelmente instáveis e incapazes de oferecer a segurança ontológica que nos prometiam. (CUNHA, 2019, p.27)

Já Paul B. Preciado alcançará pontos mais próximos ao que pretendemos comentar, abordando reiteradas vezes em seus estudos a industrialização, a máquina, a tecnologia (concebida como uma ordem anatômico-política de poderes, conceitos, saberes e transformações). Em meio às propostas de uma prática e uma teoria contrassexual, o autor interpelará inclusive as reflexões mais centrais de Antropologia do ciborgue:

[O] ciborgue não é um sistema matemático e mecânico fechado, mas um sistema aberto, biológico e comunicante. O ciborgue não é um computador, e sim um ser vivo conectado a redes visuais e hipertextuais que passam pelo computador, de tal maneira que o corpo conectado

1 MORAES, Eliane Robert (2017). O corpo impossível: a decomposição da figura humana: de Lautréamont a Bataille. 2.ed. São Paulo: Iluminuras.

2 Eduardo Leal Cunha. "A normalização das homossexualidades e os destinos do masculino". Revista CULT, 22(242). 
se transforma na prótese pensante do sistema de redes. (PRECIADO, 2017, p.167)3

O ensaio de Tomaz Tadeu - "Nós, ciborgues: O corpo elétrico e a dissolução do humano" -, passa ao largo das reflexões a respeito da/s sexualidade/s. Contudo, encontra larga margem de consonância à referência anterior, pois a questão central do autor é "onde termina o humano e onde começa a máquina?" (TADEU, 2016, p.10). A essa questão ele responderá comentando as transformações impostas ao corpo humano pela máquina: a ubiquidade do ciborgue, a interpenetração promíscua entre máquina e humano, a artificialização - mecanização e eletrificação - do humano, e a humanização subjetivação - otimizada da máquina.

O embaraço entre algumas fronteiras organizantes do pensamento ocidental também será apontado por Tadeu: o que separa ciência e política, tecnologia e sociedade, natureza e cultura? E, novamente, a questão colocada acima:

[S]e existe [...] uma criatura tecno-humana que simula o humano, que em tudo parece humana, que age como um humano, que se comporta como um humano, mas cujas ações e comportamentos não podem ser retroagidos a nenhuma interioridade, a nenhuma racionalidade, a nenhuma essencialidade, [...] então é a própria singularidade e exclusividade do humano que se dissolve. A ideia do ciborgue, a realidade do ciborgue [...] coloca em xeque a originalidade do humano. (TADEU, 2016, p.13-14)

As noções, ressonâncias teóricas e bases conceituais descritas acima correspondem ao território pelo qual os textos subsequentes

3 Paul B. Preciado. Manifesto contrassexual. São Paulo: n-1 edições. 
do volume se moverão. Responderemos, então, ao convite de Tomaz Tadeu (2016, p.14), e nos integraremos/plugaremos/ligaremos a essa corrente.

\section{"VOCÊ É UM CIBORGUE": UM ENCONTRO COM DONNA HARAWAY}

O jornalista e romancista britânico-indiano Hari Kunzru assina o texto seguinte, "Você é um ciborgue: Um encontro com Donna Haraway". Novamente o corpo humano interpelado e invadido pela tecnologia é o ponto de partida: "[q]uando a tecnologia atua sobre o corpo, nosso horror mescla-se, sempre, com uma intensa fascinação. Mas de que forma, exatamente age a tecnologia? E em que profundidade ela penetrou sob a membrana de nossa pele?" (KUNZRU, 2016, p.19). Em busca de respostas, Kunzru se volta para o bucólico Condado de Sonoma, Califórnia, às margens do Russian River, onde encontrará Donna J. Haraway.

Autora de obras como Gender, Race and Nature in the World of Modern Science (1989) e Simians, Cyborgs and Women: The Reinvention of Nature (1991) - ambas não traduzidas para o português -, Donna Haraway é mais conhecida no Brasil pelo impacto do canônico ensaio "Manifesto Ciborgue: Ciência, tecnologia e feminismo-socialista no final do século $X X^{\prime \prime}$. Enquanto professora de História da Consciência na Universidade da Califórnia, Santa Cruz, Haraway destacou-se como uma das poucas pensadoras a teorizar de forma contundente e sistemática a respeito das relações entre ciência, tecnológica e política, e entre a humanidade e as máquinas. Influenciadora do 
debate em áreas aparentemente tão diversas como a Primatologia e a Filosofia, também é referência nos debates contemporâneos a respeito de gênero, sexualidade e biotecnologia, e nome corrente nas reflexões do/s Feminismo/s, do Ciberfeminismo, da Bioética, da Engenharia Genética e dos Estudos Animais.

O relato de Hari Kunzru responderá, no volume em questão, a uma valiosa dupla operação. A princípio, dará voz a Donna Haraway para que explique, com certa dose de informalidade, pontos centrais da reflexão conduzida no Manifesto Ciborgue. Por exemplo, a respeito das conexões entre o ciborgue e as lutas feministas, Haraway afirma que

[a]s preocupações feministas estão dentro da tecnologia [...]. Estamos falando de coabitação: entre diferentes ciências e diferentes formas de cultura, entre organismos e máquinas. Penso que as questões que realmente importam (quem vive, que morre e a que preço) [...] estão corporificadas na tecnocultura. Elas não podem ser resolvidas de nenhuma outra maneira. (HARAWAY, Apud KUNZRU, 2016, p.28)

Além dessas explicações, introduções, e reflexões posteriores, uma série de exemplos bastante cotidianos virá somar-se àqueles já presentes no Manifesto: a pensadora comentará a respeito das redes político-biotecnológicas que unem a plantação de arroz, a imigração ilegal e a intoxicação por pesticidas. Ou ainda, a respeito da "interação entre medicina, dieta, práticas de treinamento, vestimentas e fabricação de equipamentos, visualização e controle do tempo" (HARAWAY, Apud KUNZRU, 2016, p.23), que transforma o esporte olímpico em uma rede tecnocultural internacional. 
A visita de Kunzru a Haraway suscitará também interessantes alusões a respeito da promiscuidade entre o discurso tecnológico e a linguagem chã do dia a dia. O jornalista menciona "uma surpreendente disposição", demonstradas pelos humanos dos anos 90, "para se compreenderem como criaturas conectadas entre si por meio de redes" (KUNZRU, 2016, p.27), ao que Haraway complementa:

[s]e começarmos a falar com as pessoas sobre como elas preparam seu jantar ou que tipo de linguagem utilizam para descrever problemas em seu casamento, é muito provável que obtenhamos respostas que se expressam em termos de circuitos, de quebra de comunicação, de ruído e sinal. (HARAWAY, Apud KUNZRU, 2016, p.27)

Outra potência relevante do relato de Kunzru avança um pouco mais em direção às estratégias de acessibilidade do pensamento conforme comentadas acima. Ao interpelar Donna Haraway em sua intimidade doméstica, caracterizando-a como alguém que mais se parece a "uma tia querida" (KUNZRU, 2016, p.20) que a um ciborgue, o relato colabora para dissolver a impressão do ciborgue como algo totalmente alheio e exterior a nós. Ao recuperar a trajetória acadêmica da pensadora, associando-a às mutações em seu pensamento e em seu modo de vida, Kunzru parece nos dizer que se essa mulher, sentada em sua varanda, bebendo cerveja e acariciando seu gato, dotada de um passado profissional, afetivo, político, se essa mulher tão semelhante a nós está convicta de ser um ciborgue, por que não haveríamos nós todos de sê-lo também? Afinal, o mundo de Donna Haraway é também o nosso: "um mundo de facções em guerra, ideologias em conflito, oposições em choque: o estado e o povo, o gay e o heterossexual, o capitalismo e 
o comunismo, o humano e o animal, as pessoas e as máquinas. [...] obviamente, uma loucura completa" (KUNZRU, 2016, p.32).

\section{MANIFESTO CIBORGUE: CIÊNCIA, TECNOLOGIA E FEMINISMO-SOCIALISTA NO FINAL O SÉCULO XX}

Donna J. Haraway afirma trazer um ensaio pleno de ironia e como a maioria das ironias -, causa incômodo, promove um esforço em compreender uma sociedade além dos paradigmas atuais de construção de relações. Haraway propõe uma sociedade para além da existência das fronteiras.

A figura do ciborgue proposta pela estudiosa trata-se de

um organismo cibernético, um híbrido de máquina e organismo, uma criatura de realidade social e também uma criatura de ficção. Realismo social significa relações sociais vividas, significa nossa construção política mais importante, significa uma ficção capaz de mudar o mundo. (HRAWAY, 2016, p.36)

O ciborgue advém da necessidade de refletirmos as fronteiras que demarcam nossa sociedade, isto é, de "imaginar um mundo sem gênero, que será talvez um mundo sem gênese, mas talvez, também, um mundo sem fim. A encarnação ciborguiana está fora da história da salvação" (HARAWAY, 2016, p.37-38). Colocase, portanto, em xeque as dicotomias. Anula-se os domínios de opressão, a estrutura social atual, em cujo cerne está o homem original como elemento primordial:

Com o ciborgue, a natureza e a cultura são reestruturadas: uma não pode mais ser o objeto de apropriação ou de incorporação pela outra. Em um mundo de ciborgues, as relações para se construir 
totalidades a partir de respectivas partes, incluindo as da polaridade e da dominação hierárquica, são questionadas. (HARAWAY, 2016, p.39)

É necessário, portanto, refletir a quebra das fronteiras a partir de três fronteiras cruciais: humano / animal, humano / máquina e físico / não-físico.

Ao colocar em xeque as dicotomias, Donna Haraway propõe pensar a definição de "experiência das mulheres", ou seja, o que demarcaria a categoria de "mulher". Há uma essência do sujeito mulher? Um conceito unificador e totalitário?

Haraway mostra como os feminismos socialista e marxista expuseram a não inocência da categoria "mulher", pois essa revela estruturas de dominação aprioristicamente definidas por um sistema hierárquico. Logo, é necessário compreender que "mulher" é um mito político. A partir daí, a estudiosa propõe refletir "mulher" não por meio de identidades e sim afinidades, pois as identidades são "contraditórias, parciais e estratégicas" (HARAWAY, 2016, p.47), criando, portanto, taxonomias infinitas que não agregam, e sim excluem. Logo, pensar em afinidades em vez de identidades é pensar em uma unidade política para "enfrentar, de forma eficaz, as dominações de 'raça', de 'gênero', de 'sexualidade' e de 'classe"' (HARAWAY, 2016, p.52). Com isso, o feminismo ciborgue tem "que argumentar que 'nós' não queremos mais nenhuma matriz identitária natural e que nenhuma construção é uma totalidade" (HARAWAY, 2016, p.52).

Os rearranjos das relações sociais desenvolveram uma possível unidade política enraizada nas demandas que apresentam uma diferença relativa no olhar populacional. Esse 
olhar, a priori caracterizado por uma sociedade que visava um sistema industrial estritamente voltado ao trabalho, passa pela transição de acoplar o lazer e a "informática da dominação" em suas vivências.

Essa transição é acompanhada por mudanças que regem o cenário da sociedade e englobam vários segmentos sociais, comportamentais e ideológicos. Ademais, com a evolução tecnológica, o imbricamento entre o real e o virtual acaba com o conceito de natural, conforme sustenta Dona J. Haraway.

Desse modo, as transformações etnográficas estão em constante movimento, o que não possibilita uma determinação ou planejamento, tornando os procedimentos adotados pelas estratégias de controle baseados em dados probabilísticos e estatísticos para "convencer" determinado grupo social. A pensadora destaca que, no caso das mulheres, a escolha por ser mãe carrega vários estereótipos:

[a] situação real das mulheres é definida por sua integração/ exploração em um sistema mundial de produção / reprodução e comunicação que se pode chamara de "informática da dominação". (HARAWAY, 2016, p.63)

Como apontado, esse conjunto de relações sociais e da tecnologia são cruciais nas relações vivenciadas diariamente por mulheres e demais grupos, pois remodelam os corpos por meio de ferramentas que são corporificadas ao seu cotidiano. Além disso, o fluxo de informações e controle que os indivíduos estão submetidos consiste em determinar um número cada vez maior de conteúdos compartilhados e produzidos. 
Outro aspecto destacado pela pensadora é a visão do corpo como um "sistema cibernético de comunicação", o qual se relaciona à situação reprodutiva da mulher, permeada pela intervenção de novas tecnologias e pela estética. Desse modo, destaca que "[o] bviamente saber quem controla a interpretação das fronteiras corporais na hermenêutica médica é uma questão feminista importantíssima." (HARAWAY, 2016, p.74). Assim a reformulação das expectativas e a obtenção do remodelamento corporal são fatores centrais para vivenciar os meios sociais e pessoais.

A princípio, verifica-se que, com o advento da "Nova Revolução Industrial", surgiram as novas divisões do trabalho, favorecendo o enfraquecimento dos agrupamentos familiares. Esse acontecimento envolve questões como consumo, produção, sexualidade, reprodução e foi nomeado por Richard Gordon como "economia do trabalho caseiro".

Essa nova modalidade caracterizada, em um primeiro momento, por estabelecer trabalhos direcionados apenas para o público feminino passa a ser executado também por homens. Em vista disso, os lugares de trabalho que anteriormente se reduziam a determinado gênero, passam a integrar uma nova escala na qual são repensados os papéis e as relações existentes na sociedade. De acordo com Haraway, isso "torna-se possível por meio das novas tecnologias, embora não seja causado por elas" (HARAWAY, 2016, p.70).

Com a descentralização da mão de obra, as consequências de novos arranjos econômicos e tecnológicos surgem devido à intensificação da pressão e da cobrança em relação aos papéis desenvolvidos por mulheres e a feminização da pobreza, advinda da 
maioria dos lares serem chefiados por mulheres que ganham menos que homens para desempenharem as mesmas funções, sendo responsáveis por suprir todas as carências, afetivas ou financeiras.

É importante destacar ainda que as mulheres negras sofrem mais nesse processo devido a várias questões, sendo a raça, a sexualidade e a classe os principais norteadores das consequências relativas às políticas de gênero e raça. Além disso, é notório que as condições a que estão submetidas são ainda piores do que as vivenciadas por mulheres brancas.

Adiante, a pensadora discorre sobre a fuga das mulheres negras dos serviços domésticos mal remunerados para a ocupação de cargos em escritórios e a pressão sofrida pelas adolescentes nas áreas industrializadas do Terceiro Mundo que são diretamente as provedoras da principal fonte de renda das famílias. Essas fases do capitalismo desencadearam posteriormente modelos problemáticos e desiguais na formação das famílias, sendo esses

1) a família nuclear patriarcal, estruturada pela dicotomia entre o público e o privado e acompanhada pela ideologia burguesa branca de separação entre a esfera pública e a privada e pelo feminismo burguês anglo- americano do século XIX; 2) a família moderna mediana (ou imposta) pelo estado de bem-estar e por instituições como o salário-família, com um florescimento de ideologias heterossexuais a-feminista, incluindo suas versões críticas desenvolvidas em Greenwich Village, em torno da Primeira Guerra Mundial; e 3) a "família" da economia do trabalho caseiro, caracterizada por sua contraditória estrutura de casas chefiadas por mulheres, pela explosão dos feminismos e 
pela paradoxal intensificação e erosão do próprio gênero. (HARAWAY, 2016, p.71-72)

Nesse contexto de divisão de grupos familiares, de acordo com Dona Haraway, as novas tecnologias desencadearam o desemprego estrutural a medida que a mão de obra humana foi substituída pela robótica e tecnologias que mecanizaram os trabalhos. O que afetaria também as relações sociais, os vínculos afetivos, a sexualidade e a reprodução.

Ademais, é apontado como a estrutura social é fortemente bimodal: de um lado altas tecnologias e um bombardeio de informações; de outro, uma grande quantidade de indivíduos que vivem à margem da sociedade, sem acesso à alfabetização e ao mercado de trabalho, em especial, a pensadora destaca, "pessoas de cor". Porém, esses indivíduos estão expostos e controlados por meios tecnológicos que vão das redes de entretenimento até os demais meios comunicativos disponíveis.

Acerca do contexto das mulheres no circuito integrado, Haraway sintetiza "a localização histórica das mulheres nas sociedades industriais avançadas, considerando que essas posições foram reestruturadas, em parte, por meio das relações sociais da ciência e da tecnologia" (HARAWAY, 2016, p.76). Ou seja, a imagem de uma rede ideológica que sugere uma profusão de espaços e identidades e a permeabilidade das fronteiras no corpo pessoal e no corpo político. A ideia de "rede" evoca tanto uma prática feminista quanto uma estratégia empresarial multinacional. Tecer é uma atividade para ciborgues oposicionistas.

Por fim, a estudiosa propõe-se a pensar novamente acerca do mito sobre identidades e sobre fronteiras, realizando um percurso 
sobre a questão dos dualismos: eu x outro, mente x corpo, cultura $\mathrm{x}$ natureza, macho x fêmea, civilizado x primitivo, realidade xaparência. Com isso, demonstra que as ficções-científicas feministas sobre ciborgues têm a tarefa de recodificar a comunicação e a inteligência a fim de subverter o comando de controle das estruturas sociais.

\section{GENEALOGIA DO CIBORGUE}

Um outro texto de Hari Kunzru, "Genealogia do ciborgue", encerra o volume. Esse breve ensaio parte da inquietante constatação de que o primeiro ciborgue do mundo teria sido um rato de laboratório. Ao final dos anos cinquenta, como parte de um programa experimental no Hospital de Rockland, o animal teve uma bomba osmótica implantada em seu corpo, a qual injetava doses controladas de substâncias em seu organismo, visando provocar alterações em seu funcionamento fisiológico.

A definição de ciborgue, portanto, seria: "parte animal, [...] parte máquina" (KUNZRU, 2016, p.121). Essa primeira definição teria sido cunhada por Manfred Clynes e Nathan Kline, um engenheiro e um psiquiatra, os próprios inventores do termo "ciborgue". Em um artigo de $1960^{5}$, republicado em livro mais de três décadas depois, em $1995^{6}$, os autores atribuíam ao termo o ideal de "um homem melhor adaptado aos rigores da viagem espacial", cujo corpo constituiria um híbrido entre humano e máquina (KUNZRU, 2016, p.121).

As várias facetas do ciborgue serão também comentadas por Kunzru. Ao mesmo tempo projeto técnico, sonho científico,

5 CLYNES, Manfred E.; KLINE, Nathan S. "Cyborgs and space". Astronautics, 5(9), 26-27; 74-76.

6 CLYNES, Manfred E.; KLINE, Nathan S. "Cyborgs and space”. In: The cyborg handbook. Nova lorque; Londres: Routledge. p.83-92. 
ideal militar, criatura de ficção científica e assunto do horário nobre televisivo, o ciborgue se encontrará em um espaço de tensionamento. De um lado, a possibilidade de fuga das limitações corporais humanas - ficcionalizada em figuras como o SuperHomem e o Capitão América -, de outro, o imaginário em torno de robôs, autômatos e seres artificiais, referidos desde o épico indiano Mahabharata, datando de 300 a.C. A tensão entre ficção, ideal científico, e prática científica de fato, incidiria no que vem a ser a realidade do ciborgue:

[u]ma máquina constituída de uma combinação e pulmão e coração [...] utilizada para controlar a circulação sanguínea de uma moça de 18 anos durante uma operação em 1953. Um homem de 43 anos [que] recebeu o primeiro implante de marca passo (sic.) em 1958. (KUNZRU, 2016, p.122-123)

Um marco divisório na história do ciborgue, segundo Kunzru, seria sua aproximação da tecnologia da informação, diferenciando-o de seus ancestrais mecânicos. $\mathrm{O}$ autor recorre a Haraway nesse ponto: os ciborgues "são máquinas de informação. [...] trazem dentro de si sistemas causais circulares, mecanismos autônomos de controle, processamento de informação - são autômatos com uma autonomia embutida" (HARAWAY, Apud KUNZRU, 2016, p.123).

Nessa esteira, ganham relevância a Guerra Fria, a cibernética e a figura do inaugurador dessa ciência, Norbert Wiener. O lançamento de seu Cybernetics, or control and commucation in the animal and the machine”, em 1948, cunharia o termo "cibernética". Posteriormente, essa ciência seria identificada como aquela "que explicaria o mundo

7 WIENER, Norbert (1948). Cybernetics: Or control and Communication in the Animal and the Machine. Paris: Hermann \& Cie; Cambridge: MIT Press. 
como um conjunto de sistemas de feedback, permitindo o controle racional de corpos, máquinas, fábricas, comunidades e praticamente qualquer outra coisa", ou seja, "uma ciência universal da comunicação e do controle" (KUNZRU, 2016, p.124-125).

No ambiente da Guerra Fria, alimentados pelo ideal de superar as limitações do corpo humano, os pesquisadores de ciborgues teriam se empenhado em interpretar seus problemas sob a ótima da cibernética de Wiener:

O corpo era apenas um computador de carne, executando uma coleção de sistemas de informação que se auto-ajustavam em resposta aos outros sistemas e a seu ambiente. Caso se quisesse construir um corpo melhor, tudo que se tinha a fazer era melhorar os mecanismos de feedback ou conectar um outro sistema. (KUNZRU, 2016, p.125)

Kunzru finaliza sua genealogia descrevendo a dissolução da cibernética como ciência, vítima de suas próprias limitações, tais como a analogia completa e incoerente entre os mecanismos de controle e comunicação das máquinas, dos animais e da sociedade. Contudo, aponta o autor, serão vários os desdobramentos do sonho de Norbert Wiener de fundar uma ciência universal. Novas áreas surgiram, como as ciências cognitivas, pesquisas em campos como a Inteligência Artificial receberam maior atenção e investimentos, e sobretudo, dois resíduos culturais importantes foram deixados. De início, a "descrição do mundo como uma coleção de redes"; em seguida, a "intuição de que não existe uma distinção tão clara entre pessoas e máquinas" (KUNZRU, 2016, p.126).

Elucidativo a respeito do ciborgue que paira fantasmagoricamente por todo o volume Antropologia 
do ciborgue, o ensaio de Kunzru repete um esforço que já identificamos em sua entrevista a Donna Haraway. Dando relevo às juntas, próteses, implantes auditivos e óticos, à cirurgia cosmética, aos bancos de dados (como próteses para a memória humana), e ao mesmo tempo às tecnologias de otimização dos corpos-militares, o autor descortina o quanto de nós está nos ciborgues, e vice-versa, bem como quantas estranhezas tecnológicas passam ao largo de nossa reflexão cotidiana. 